\title{
Using cermet inserts in HSC technology when machining hard-to-machine tool steel
}

\author{
I. Zetková \& M. Zetek \\ Regional Technological Institute, \\ University of West Bohemia, Czech Republic
}

\begin{abstract}
Shape reduction before and after deposition of the cutting edge is a very topical problem. The shape reduction improves the quality of the cutting edge and increases the cutting tool life, so it is very important for the users. These methods are mainly used for cutting tools from sintered carbide and tool steel, but there has been no research on edge reduction of cermet cutting tools. So this paper deals with the influence of the microgeometry of cermet inserts on cutting tool life when milling tool steel EN ISO X210Cr12 with hardness $52 \mathrm{HRC}$.

Keywords: cermet, cutting tool life, edge modification, HSC technology.
\end{abstract}

\section{Introduction}

When cermet cutting tools are used there are a lot of problems which must be constantly addressed. One of them is their fragility which influences tool life and therefore the reliability of the cutting process. When machining hard-to-machine material using HSC technology the fragility causes formation of notches and this causes destruction of the entire cutting tool [1,2]. It influences the surface quality, accuracy of the machined surface and especially the shape integrity of the machined surfaces. Therefore, we try to prevent the most common problems in the following ways: optimizing tool geometry, optimizing microgeometry and using thin layers which are deposited on the functional shapes [3]. One of the advantages of cermet cutting tools is the ability to minimize the cutting liquid (MQL technology) or completely remove process fluids (DC) [4]. Therefore, this contribution will deal with verifying and describing these limiting factors which influence cutting tool efficiency and quality of workpiece. During machining the cutting tool life, the type and size of edge wear and quality of finished surface 
will be monitored. The milling head with a circular insert of cermet with different edge modifications will be used. Experiments will be conducted using HSC technology when machining tool steels EN ISO X210Cr12 D3 with hardened 52 HRC. All the experiments will be in the dry mode.

\section{Experiment}

\subsection{Cutting tool}

For the tests a milling head with two circular cermet inserts with diameter 32 $\mathrm{mm}$ was used. The insert diameter was $12.025 \mathrm{~mm}$ and different modifications of the edge were used. The first one was drag-finishing the second was dry sanding and third one was edge without modification (after grinding) (Figure 1). For the grinding, different grinding tools were used which influence insert roughness. The grinding was done by the company HamFinal which specialises in the production of cermet cutting tools in the Czech Republic. During machining only one insert was cut and the second one was ground. Tool geometry was negative axial rake angle $\gamma_{\mathrm{A}}=-13^{\circ}$, radial rake angle $\gamma_{\mathrm{R}}=-16^{\circ}$.

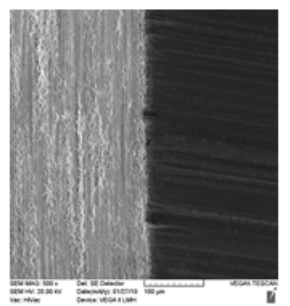

(a)

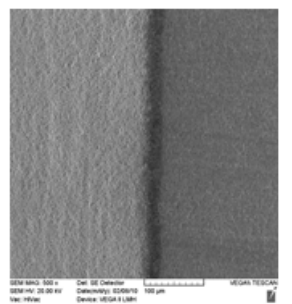

(b)

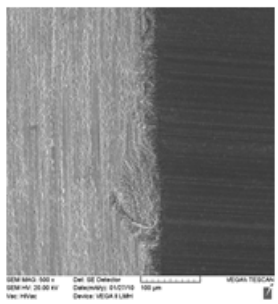

(c)

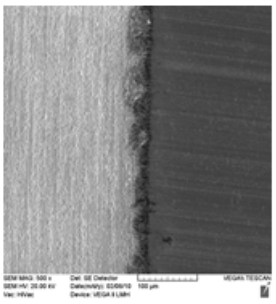

(d)

Figure 1: (a) Insert after grinding with coarse grain; (b) insert after dry sanding - grinding with coarse grain; (c) insert after grinding with fine grain; (d) insert after drag-finishing - grinding with fine grain.

\subsection{Workpiece}

Tool steel AISI D3 (EN ISO X210Cr12) with hardness 52HRC was machined. This steel is high-chromium ledeburitic alloy steel so it is a hard-to-machine material. This is because of the high percentage content of the carbon which causes the formation of hard carbide papers and it causes quicker increasing of tool wear.

\subsection{Measuring equipment}

For the experiments the following equipment was used:

- Vertical milling center MCV 750A

- MicroCAD, IFM G4, confocal microscope Olympus LEXT OLS 3000 - for measuring the edge radius

- Optical microscope Multicheck PC500 - for measuring the tool wear

- Roughness MITUTOYO Surftest SJ - 201 


\subsection{Cutting condition}

When machining with cermet cutting tools the cutting environment is dry and it eliminates the formation of heat shock and cracks. Secondly, dry machining causes a decrease of costs. During the test a lot of experimental measuring was made with many variables values.

The cutting inserts edge was modified with these methods:

- without modification but the inserts were ground with fine grain mark "V-I" and coarse grain mark "V-II";

- drag-finishing - mark " $F$ ";

- dry sanding - mark "S".

So these methods of modification and different roughness after grinding and their combination influence the value of the cutting edge radius. These differences are shown in Figure 2.

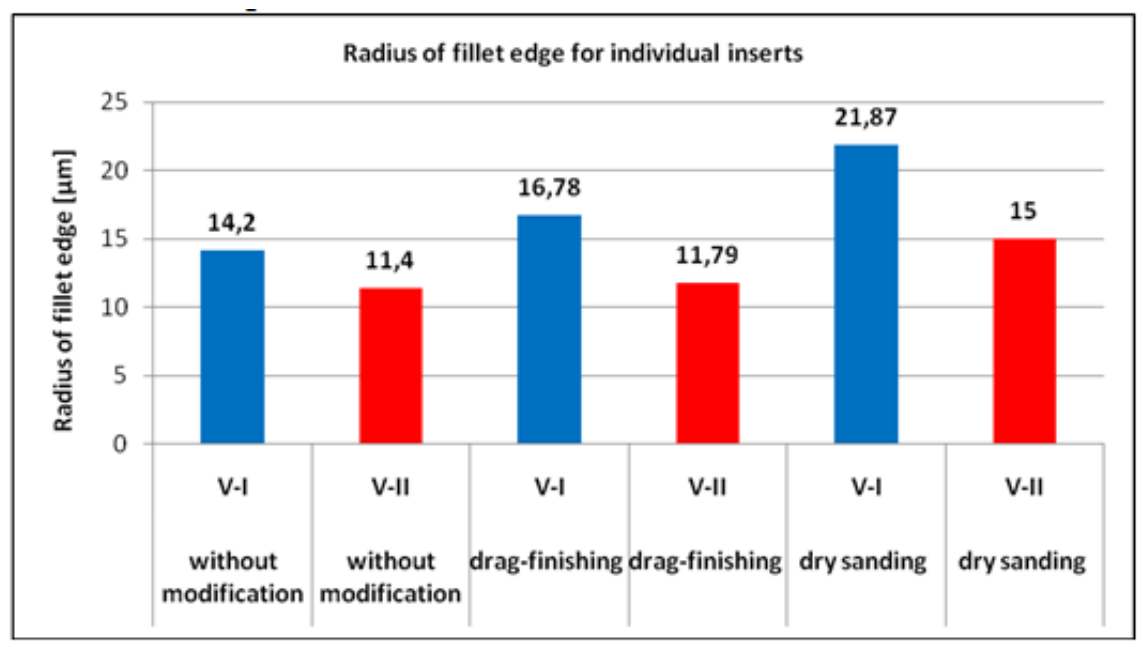

Figure 2: Insert after drag-finishing - grinding with fine grain.

Figures 3 and 4 show the visualization of the real shape of the cutting edge. Visualization in Figure 7 is made by the laser confocal microscope Olympus LEXT OLS 3000. Measuring accuracy of these methods depends on the operators because the radius of the cutting edge is evaluated manually. Visualization in Figure 8 is made by the MicroCAD system. This equipment is developed for the measuring of these small radiuses on cutting tools so all functions and evaluations are automatically carried out. This means that measuring is more accurate than the confocal microscope.

Six different edge radiuses were used for the test. During the test the influence of the radius value on the tool life and workpiece roughness were monitored. A number of cutting inserts with modifications were prepared for the final test so many tests were made with the inserts without modification but for 

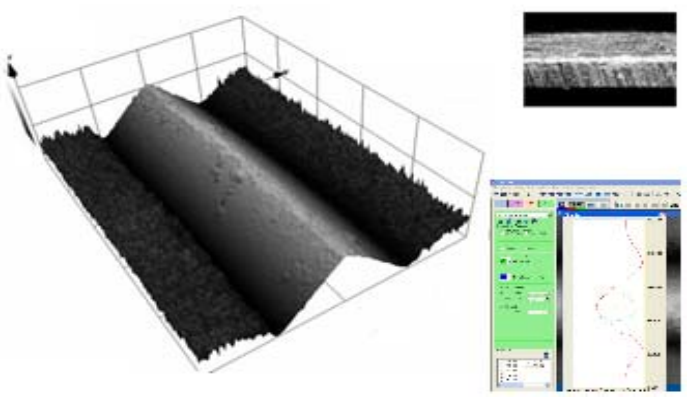

Figure 3: Visualization of the insert edge by confocal microscope.
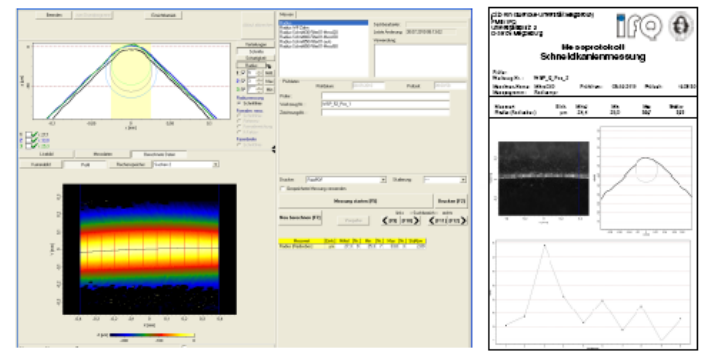

Figure 4: Visualization of the insert edge by MicroCAD.

correlation of the variable cutting condition the different roughness inserts after grinding were used.

Firstly the tests of the inserts were focused on the tool life when the cutting conditions were changed. For the tests the cutting speed $v c=450(550,620,750$, $800,900) \mathrm{m} / \mathrm{min}$ and radial depth of cut $\mathrm{a}_{\mathrm{p}}=0.5(0.75 ; 1) \mathrm{mm}$ were used and other cutting conditions such as feed $\mathrm{f}_{\mathrm{z}}=0.05 \mathrm{~mm} /$ tooth and axial depth of cut $\mathrm{a}_{\mathrm{e}}=1.5 \mathrm{~mm}$ were constant.

The graph in Figure 5 shows the tool life of the various inserts which depend on microgeometry of the cutting edge, cutting speed and depth of cut. The dark textured columns mark inserts which are affected during machining by notch wear on the back edge. The results show how strikingly the value of the edge radius influences cutting tool life. The influences of the microgeometric modifications are even greater than the effect of the cutting speed. If the edge radius increases, the cutting tool life decreases. A significant proportion of the tool life is also micro modification of the edge. From the graph it is evident that when $800 \mathrm{~m} / \mathrm{min}$ cutting speed and depth of cut $0.5 \mathrm{~mm}$ is used the inserts after grinding have better tool life than the inserts after modification with the similar edge radius like inserts after grinding. So it is evident that the inserts roughness has a dominant effect on the cutting tool efficiency. 
The longest tool life was monitored during cutting speed $550 \mathrm{~m} / \mathrm{min}$ and depth of cut $0.5 \mathrm{~mm}$. When the cutting speed decreases the tool life decreases too, but when the cutting speed increases the tool life decreases only to the cutting speed $800 \mathrm{~m} / \mathrm{min}$ and under these cutting conditions the tool life increases. It is caused by the high temperature before edge which decreases the machined workpiece hardness and strength and this effect is typical for HSC machining. This theory is confirmed by the value of the cutting forces which decrease too.

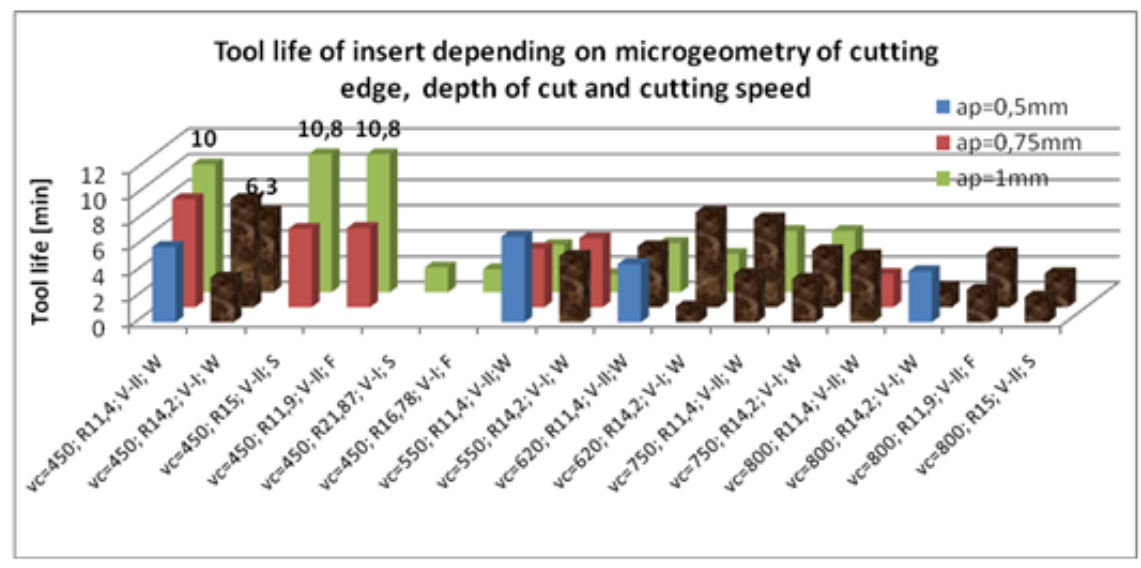

Figure 5: Influence of the edge radius on the tool life.

Secondly the tests were focused on the workpiece quality when finishing and the Ra roughness was monitored. Generally for the finishing higher cutting speed and smaller depth of cut is used. So the depth of cut $0.5 \mathrm{~mm}$ was used and the cutting speed was changed.

When comparing the results in Figure 6 the edge radius and modification is evident. The graph shows that the tool without modifications has better roughness than tools with modification. It is caused by the notch of the edge without modification but their values are never bigger than the limit value.

When the different cutting conditions are compared by the volume of the machined material it is evident that the optimal cutting speed is $800 \mathrm{~m} / \mathrm{min}$ and $550 \mathrm{~m} / \mathrm{min}$ for the depth of cut $0.5 \mathrm{~mm}$ for the inserts without modification which were grinded by the coarse grain wheel.

Thirdly the increasing of the depth of cut was monitored. When the depth of cut is increased the graph shape is moved to the right, i.e. to the lower cutting speed. Increasing of the depth of cut to $0.75 \mathrm{~mm}$ means that the cutting speed must be lower, but only to the specific value. It was monitored that the tool life decreases, and bat this value tool life increases. It is evident, that the main point is the limit of the HSC technology. So it is confirmed by the type of the chip, which were hot and this is typical for HSC technology. From these results we can conclude that HSC moves with the greater depth of cut to the lower cutting speed. 


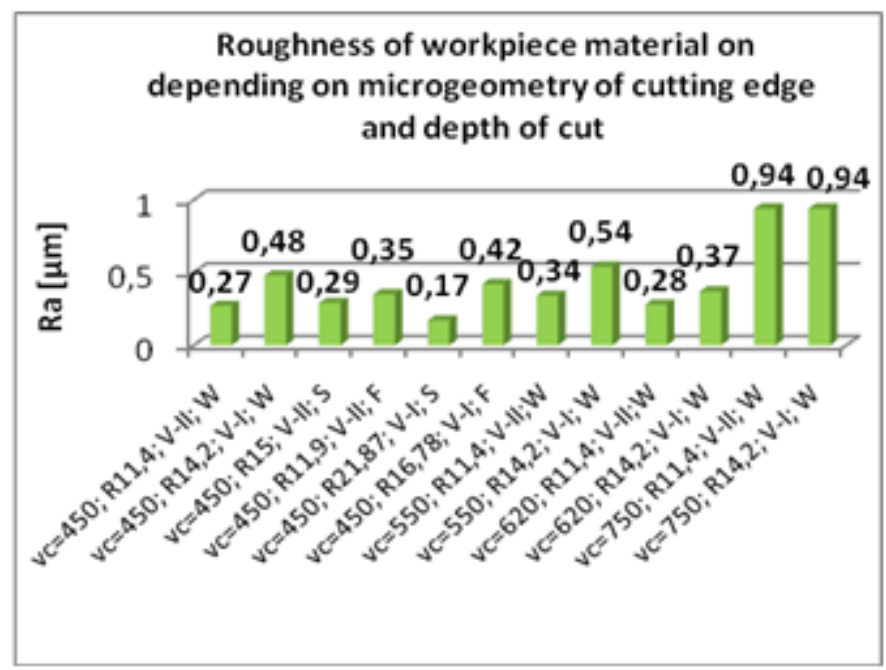

Figure 6: Influence of the cutting speed and edge radius (modification) on the workpiece roughness.

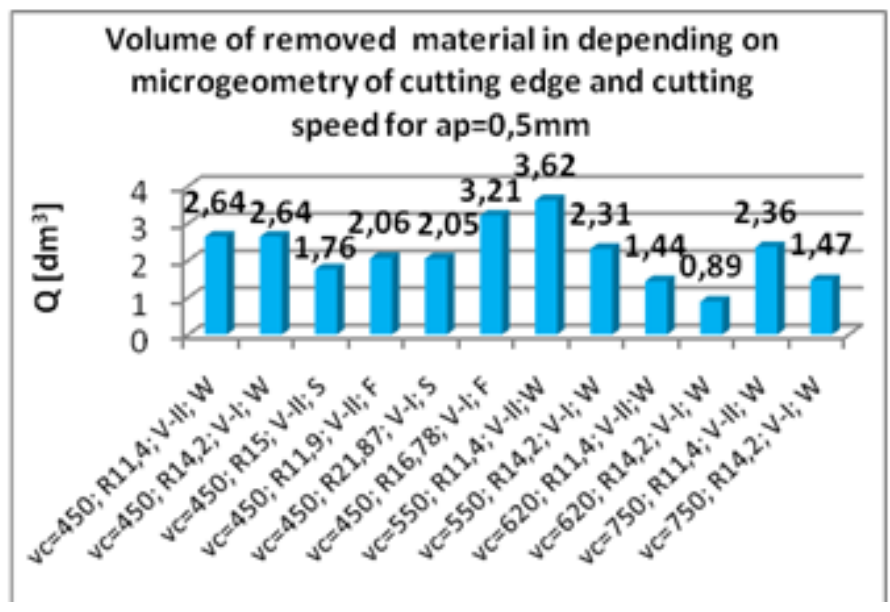

Figure 7: Influence of the cutting speed and edge radius (modification) to the volume of the machined material.

When the depth of cut increases to $1 \mathrm{~mm}$ it causes the tool life to increase over $10 \mathrm{~min}$. It is more than $40 \%$ when the same cutting speed and half feed is used. This result is very important when machining this hard-to-machine material. When machined by these cutting conditions it is very important that the notch of the edge does not form and it is very important for the reliability of the cutting process. 


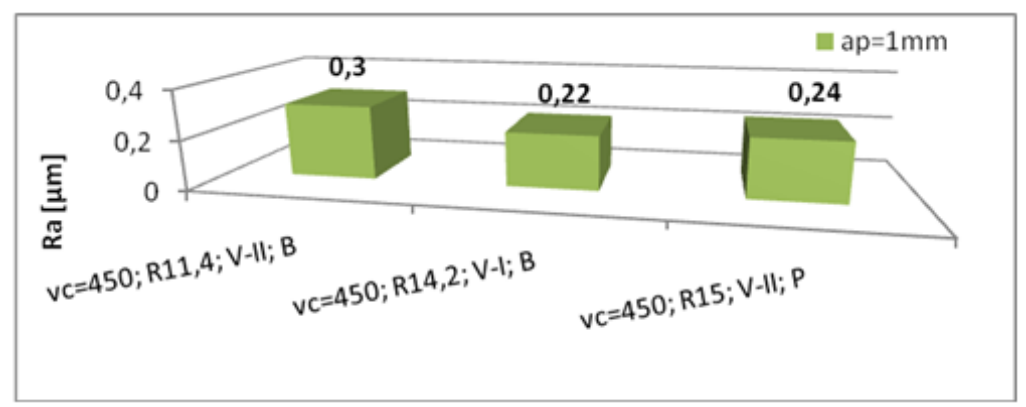

Figure 8: Workpiece roughness after 10min tool life.

Cutting inserts which are modified by dry sanding and drag-finishing have a tool life of more than $10 \mathrm{~min}$. The value of the workpiece roughness is similar to the value when the depth of cut $0.5 \mathrm{~mm}$ was used. It can be because the inserts were worn only equally in this case. When the deeper cut was used the micro modification has a greater influence on the tool life than the tool radius.

The last tests were focused on the influence of the other increase of the depth of cut ap=1.25 (1.5)mm on the tool life. For the test the cutting inserts with mark R11.4; V-II; B were used. It was detected that when the depth of cut is increased, tool life decreases for limiting tool wear $\mathrm{VBB}=200 \mu \mathrm{m}$ (Figure 9).

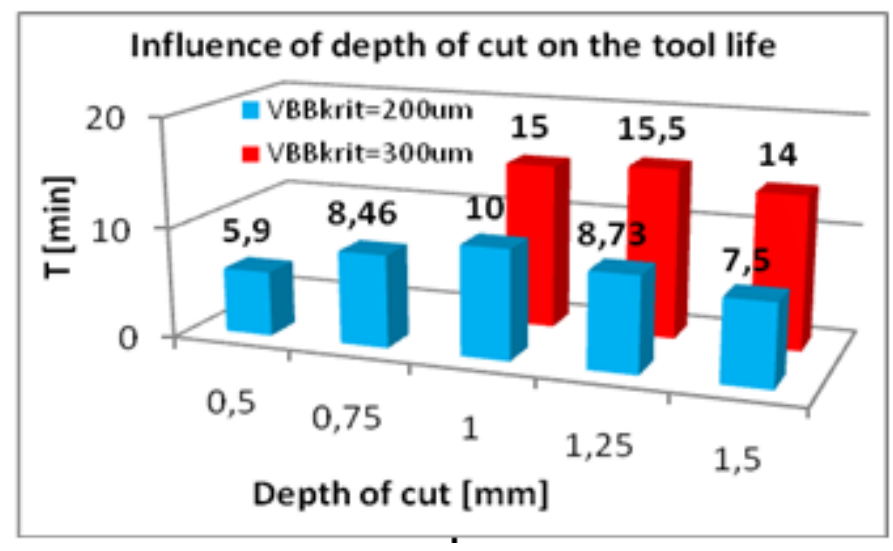

Figure 9: Influence of the depth of cut to the tool life.

Because the tool wear was even the tool wear was monitored to the limiting value $\mathrm{VBB}=300 \mu \mathrm{m}$. For all the time the tool wear was even. When the volume of the machined material was calculated it was found that the value is higher more than $90 \%$ (see Figure 10).

The roughness during the changeable depth of cut was similar when the tool wear was $\mathrm{VBB}=200 \mu \mathrm{m}$ (Figure 11$)$. 


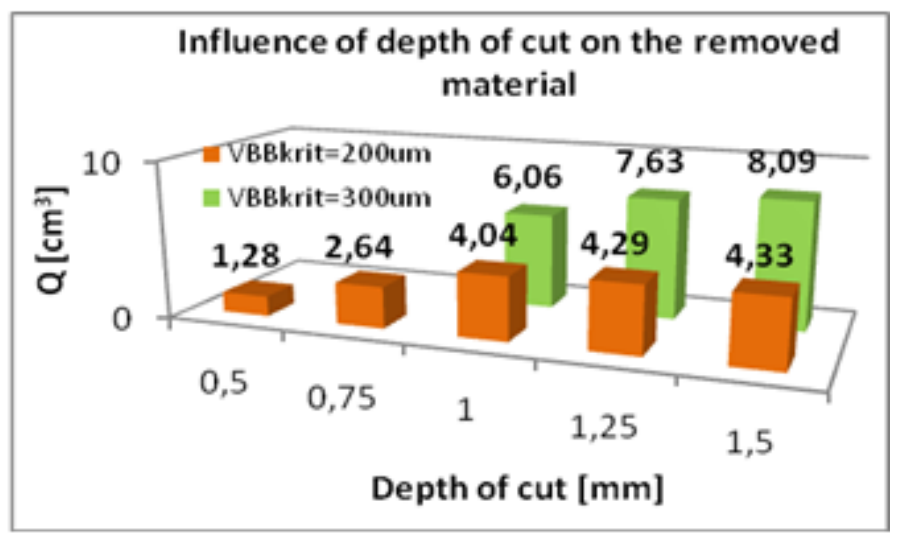

Figure 10: Influence of the depth of cut on the volume of the machined material.

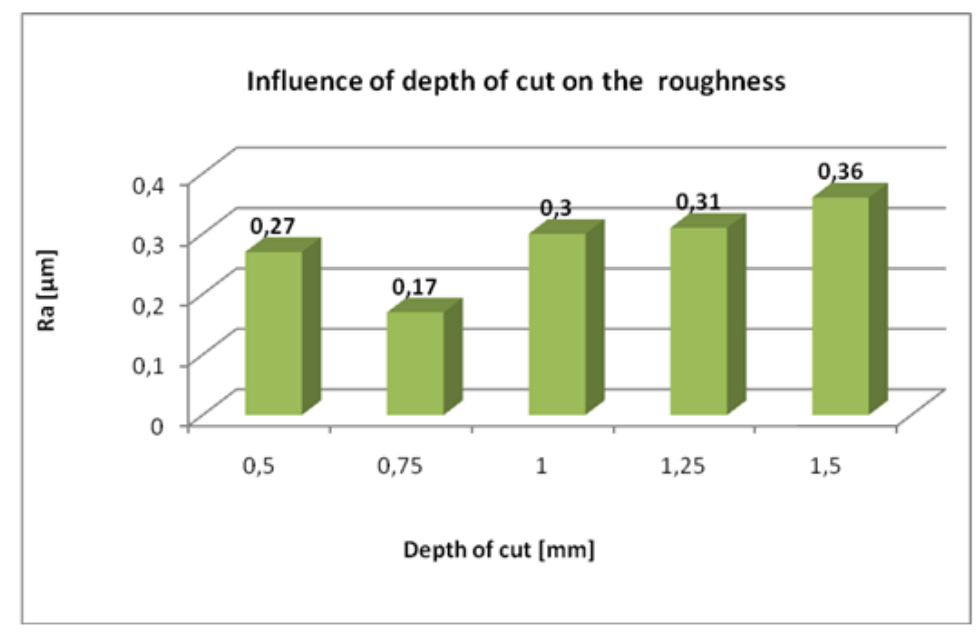

Figure 11: Influence of the depth of cut on the workpiece roughness.

\section{Conclusion}

The aim of this paper was to verify the behaviour of cermet cutting tools with various modifications of the cutting edge when cutting die steel AISI D3 and describing the influences of the cutting process on the cutting tool life and surface roughness. On the basis of these experiments cermet cylindrical inserts can be recommended as a promising material for machining tool steels primarily for use in the manufacture of molds and dies. The traditional processes of manufacturing parts from hardened steel are milling the workpiece in the annealed condition before heat treatment, followed by secondary operations such 
as electro machining, grinding and hand polishing to achieve the required geometrical sets and surface roughness. This paper shows that these nonproductive methods could be changed by HSC milling technology because the results show that this operation when the optimal cutting conditions are used is very productive, safe and reliable. If cermet is used it causes reduction of the machining time, costs and improvement of ecological aspects.

Cermet cutting tools have a very high potential in the future because at present a lot of their properties and special technologies are not used. In particular, these include optimizing micro geometric modification and standard deposition by the thin layer. This combination of surface treatment could increase their use and competitiveness.

\section{Acknowledgement}

This paper is based upon work sponsored by project "Regionální technologický institut" no. CZ.1.05/2.1.00/03.0093.

\section{References}

[1] Siller H. R., et al. Study of face milling of hardened AISI D3 steel with a special design of carbide tools. Adv. Manuf. Technol.. 2009, 40, s. 12-25

[2] Petřkovská L., Brychta J., Nováková J., Aspekty vysokorychlostního obrábění, http://web.tuke.sk/fvtpo/casopis/pdf08/2-str-67-68.pdf

[3] Zetek M., Increasing of the cutting tool efficiency by the PVD technology, Dissertation work. ZČU FST KTO. Plzeň 2009

[4] Zeman P., Šafek J; Vaněček D., Technologie HSC - VELKÉ EKONOMICKÉ I EKOLOGICKÉ PŘÍNOSY, http://technik.ihned.cz/c410004030-11353150-800000_d-technologie-hsc 